\title{
Imagination, religion and morality: An interdisciplinary approach
}

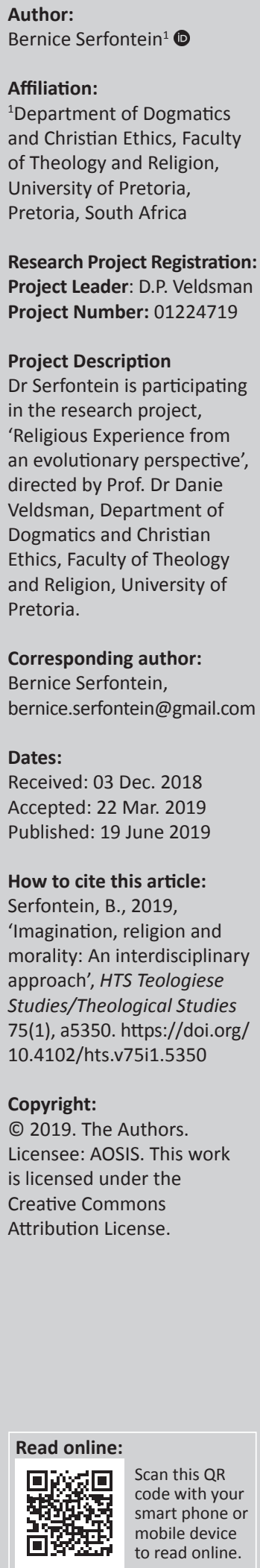

Every human society and almost all of human life are infused with ethics. How do we best understand human morality and ethics? I want to argue that responsible ethics rests on a credible understanding of what it means to be human. This article proposes that a more comprehensive understanding of the distinctive human imagination, religious awareness and morality - all of which are significant aspects of being human - will facilitate a more responsible understanding and practice of ethics. Such an understanding entails a bottom-up view, which takes seriously the exploration of the fundamental evolutionary realities of human nature, that is, a natural history of morality. The quest for understanding the propensity for imagination, religious awareness and morality can be aided by exploring the core role of the evolutionary transition between becoming and being human. Accordingly, this research combines a niche construction perspective with fossil and archaeological evidence, highlighting the role of complexity in human evolution, which adds to our understanding of a completely human way of being in the world. A distinctively human imagination is part of the explanation for human evolutionary success and accordingly our sense of morality and religious disposition. The methodology this article applies is that of an interdisciplinary approach combining perspectives of some of the most prominent voices in the modern discourses on imagination, religious awareness and morality. What results from this approach is, first, a more comprehensive understanding of the human imagination, the capacity for religious awareness and morality. Ultimately, by creatively integrating the various perspectives evident in this research - by way of a philosophical bridge theory between evolutionary anthropology and theology - this article attempts to determine whether evolutionary thought can be constructively appropriated to interdisciplinary Christian theology and ethics.

Keywords: Imagination; Religion; Religious awareness; Morality; Ethics; Evolution; Evolutionary biology; Niche construction; Philosophy.

\section{Introduction}

There is a popular assumption that religion and morality are synonymous, which is known as a top-down view of morality. This article agrees with some of the most prominent scholars in the field, who argue that the human capacity for moral awareness is built into our species. Rather than coming to us top-down from God, or any other external source, moral awareness, in their view, arises bottom-up from our capacity for empathy, cooperation and our day-to-day social interactions, which evolved through the course of our hominin history. My argument is that by exploring the evolution of both our capacity for religious awareness and morality, we might come to surprising conclusions to the question: which evolved first, morality or religion? This might influence our way of thinking about ethics, and in this case specifically Christian ethics.

In accordance with Van Huyssteen (2017a) and Fuentes (2014), I want to argue that it is our unique capacity for imagination that underpins our capacity for moral and religious awareness. Consequently, in my attempt to arrive at a more comprehensive understanding of human morality, and how it relates to ethics, I am going to explore the evolution of our distinctive imagination and how it might have laid the groundwork for the development of both religious awareness and morality. Our unique capacity to imagine enabled our ability to self-reflect. It is in this very act of reflecting on ourselves that an ethical space arises - a space in which moral reasoning functions. In this interdisciplinary work combining science and theology, I will seek to explore our human capacity for imagination, religious awareness and morality. The article will conclude with an attempt to integrate all of the perspectives explored by means of philosophical perspectives that might provide a possible bridge theory from scientific insights to interdisciplinary theology.

Note: This article is partially based on the author's thesis of the degree of Doctor of Philosophy in Dogmatics and Christian Ethics at the University of Pretoria, South Africa, with supervisor Prof. D.P. Veldsman. 
The relation to ethics, more specifically Christian ethics, will also be explored. I would like to argue that this quest to establish a more comprehensive understanding of the human self, through specifically the aspects of imagination, religion and morality, is of the utmost importance in any conversation on being human and the relation of this to ethics. Interdisciplinary accounts of these crucial aspects of being human are challenging. I argue that within the discipline of philosophy we might find some point of connection that could bridge the gap between these diverse theories and theology.

\section{Niche construction theory and human evolution}

I want to argue that an essential component of our evolutionary success is because of our being a semiotic species: the use of symbols and the development of an imagination in our perceptions of, and dealing with, the world act as a major factor in human evolutionary histories. Human beings have an imagination that is part of our perceptual and interactive reality and is a significant aspect of lived experience - consequently it is evolutionarily relevant. It is our ability to imagine solutions and realise them through collaborative effort that helped us overcome some of the greatest challenges faced in the past. As this research will show, it is realistic to accept that at some point during the past 400000 years language and hyper-complex intentionality acted 'to pin down' the more-than-material as our permanent state of being. Consequently, it formed the basis for the evolution of morality, the possibility of metaphysics, religious imagination and the propensity for religious belief as crucial parts of the uniquely human experience. To explore an evolutionary biological perspective on human imagination, religion and morality, it is necessary to describe the evolutionary theory that has been applied in this research. The pursuit of a more comprehensive understanding of human imagination, religion and morality will be conducted against the background of niche construction theory.

In evaluating the evolution of the human species, Fuentes (2014) argues that not only do human bodies and ecologies need to be explained, but also a theoretical approach needs to be developed to describe:

an effective toolkit for an evolving system that facilitates the production of simple stone tools at two million years ago, more complex stone tools and widening geographic spread one million years ago, the use and control of fire, and complex hunting and communications by 400,000 years ago, art, and increasingly complex multi-community social networks by $60-80,000$ years ago, agriculture and early cities by 5,000 years ago, and the megacities, global religions, and world economies of today. (p. 249)

Included in this toolkit are a robust imagination, and a landscape and perceptual reality within which everything, material or not, is infused with multifaceted meaning. The increasingly rapid, dynamic and deep niche construction by humans, mainly as it relates to aspects of cognitive function and social relationships, and the capability to deploy multiple modes of responding to evolutionary pressures and their associated influence on evolutionary landscapes, facilitates the evolution of the aptly named 'sapiens' by approximately 200 000-100 000 years ago (Fuentes 2014:249).

There is an expansive body of research and theory that is insufficiently captured under the two headings: 'Darwinian' and 'neo-Darwinian' (Fuentes 2009:12). In basic neoDarwinian theory, natural selection and sexual selection are prioritised as the main drivers of evolutionary change and the emergence of adaptations.

There is much more to evolution than simply the inheritance of genes. An interactive perspective on evolution is necessary, which underplays any explicit prioritisation in inheritance systems and consequently requires a purposeful move away from approaches that are limited to either social or biological focuses (Van Huyssteen 2017a:4). In this line of thought, 'evolution as construction' is the notion that evolution is never just a matter of a biologically developing organism. Rather, as Van Huyssteen (2017a:4) puts it, it is a matter of organismenvironment systems interacting and changing over time in a dynamic interactive process of niche construction as a substantial evolutionary force alongside natural selection. Almost all anthropologists would agree that human beings are constructed by, and also involved in the construction of contexts that are at once physiological, historical, behavioural, social and symbolic (Van Huyssteen 2017a:4). Following this view, then, Fuentes (2009:15, cf. Van Huyssteen 2017a:4) argues, it is crucial to see human behavioural evolution primarily as a system evolving, and not merely as a set of moderately connected or independent traits that are evolving. Niche construction is therefore a central factor in human behavioural evolution. In this view, then, any responsible discussion on the evolution of human beings should be conducted within a framework of niche construction. It is for this reason that niche construction has played a key role throughout this research project.

\section{The evolution of the distinctive human imagination}

The archaeological and fossil records suggest that the human hominin ancestors and relatives did indeed have imaginative abilities that were applied in their day-to-day living (Mithen 2007:3). These imaginative abilities were applied when, for instance, hunting and gathering or the making of stone tools were considered. Nevertheless, there is no evidence that our hominin ancestors and relatives possessed a creative imagination (Mithen 2007:3). The creative imagination is usually associated with activities such as sciences and art. This type of imagination was, according to Mithen (2007:3), most likely restricted to Homo sapiens, who appears in the fossil record 200000 years ago. Mithen (2007:3) argues that the creative imagination of $H$. sapiens was the product of a long evolutionary history in which seven key developments in biological and cultural evolution can be identified: the evolution of theory of mind capacities, a distinctively human 
life history and domain-specific intelligences, the origin of music, language, cognitive fluidity, the extension of mind by material culture and the appearance of sedentary farming communities.

In agreement with Mithen (2007), Fuentes (2017) argues that it is the capacity for creative imagination that is distinctive to the human species, and also enabled our evolutionary success and flourishing. Consequently, Fuentes (cf. 2014, 2017) takes up some of the crucial themes discussed by Mithen and develops them against the background of niche construction theory. For both Fuentes and Mithen, the human capacity for imagination developed as a reaction to the various ecological and social challenges genus Homo faced during the Pleistocene. Furthermore, Fuentes builds on and expands Mithen's notion that the capacity for imagination paved the way for the development of other human capacities such as religion and art. The combination of a niche construction perspective with fossil and archaeological evidence, emphasising the role of complexity in human evolution, adds to our understanding of a completely human way of being in this world (Fuentes 2017). An examination of the latter part of the Pleistocene is crucial in exploring the origin of imagination because that is where we can find the first material evidence of imagination (Fuentes 2014, 2017). This does not, however, imply that this is the exact starting point of the capacity for imagination. However, the simple sharp flakes and edged stones of the most primitive tool manufacturing are the first material evidence of our lineage's capacity to envision more than what is merely in front of us, and to create new form and function in the world. It all started with figuring out a better way to get food and, therefore, with imagining outcomes.

Our world is unbelievably complex and this is all because of the human capacity for imagination. But, as Fuentes (2017:286) argues, no aspect of the contemporary world is more rooted in our imaginative and hopeful capacities than faith and religious belief. Having an imagination is a crucial part of the human niche, and this imagination is a basic element required for the development of a metaphysical perception of the world, which includes the supernatural agents (cf. Fuentes 2017). If this is indeed so, one could construct both evolutionary and religious perspectives as part of the explanations for how or why humans engage in religious belief and practice. Through the course of human evolution, we have developed a niche where the imagination and symbols became key factors in our human ecology. Perhaps religious experience or awareness is a dominant consequence of the human niche, or the way human beings 'are' in the world. However, with this point one is not necessarily making an argument for exaptation (cf. Fuentes 2014:250). ${ }^{1}$

The claim is rather that this particular process arises as a component of the human niche. This takes place as it dynamically moves through the Pleistocene, and in essence Parry 2013). it is a part of the human toolkit. The human toolkit had considerable benefits, as well as potential impairments for communities and individuals in both the past and present. The genus Homo faced innumerable ecological and social challenges by the late Pleistocene. Bearing that and the complexity of their niche in mind, Fuentes (2014) states that:

one can viably argue that being able to deploy cognitive and behavioural processes that incorporate a sense of imagination and hope, while risky, could increase the likelihood of innovation and successful responses to evolutionary challenges. (p. 251)

This notion - combined with recent work studying the role of social networks, compassion and meaning, the connection between stone tool manufacturing and ritual, the early appearance of 'art' and symbols in the archaeological record, and the ongoing assertion that humans are indeed a symbolic species - provides, according to Fuentes (2014:251), an evidentiary context in which we can see the emergence of this semiotic, temporally complex and imaginative reality for the human genus.

\section{Symbolic thought and religious awareness}

For the most part of the human history as a genus and as a species (H. sapiens), the world of organised religion was very different or even absent. Religion, just like various other features of the distinctive human existence, evolved over time. Both Van Huyssteen and Fuentes, even though they work in very different disciplines, approaches and methodologies, completely agree that an essential preliminary to having religion is indeed the emergence of a human imagination as well as the embodiment of a quest for meaning as constituent of the distinctive human niche that has facilitated human flourishing as a species. There is a certain complexity that makes offering a single definition for religion difficult. Smith (2004:290-291) asserts that, in short, religion is a way in which humans organise and make meaning of the world we exist in.

Smith's (2004) explanation and broad discussion of the concept of religion is very valuable; however, I am of the opinion that such a description of religion is inadequate. Fuentes (2017:201, 2018:06:04) makes a clear distinction between the terms 'religious' and 'religion'. The term 'religious' implies the use of an individual's own capacity for belief in the context of becoming with specific perceptual, experiential and agential practices concerning the transcendental, which act to establish powerful, persuasive and long-lasting moods and motivations that may be, but are not unavoidably, linked to specific formal doctrines, institutions, practices or texts (Fuentes 2018:06:04). The term 'religion', on the contrary, is characterised as a belief in supernatural agents and counterintuitive concepts, involving symbolic rituals that assist the development of a shared experience of the world, and cultivate a differentiation of the sacred and the profane (Fuentes 2017:201). 
Even though religion is a centrally important part of being human today, there is no strong evidence that this was the case for earlier members of the genus Homo. Therefore, Fuentes (2014:242), in line with Van Huyssteen (2018:ad loc.), emphasises the importance, in acquiring a more comprehensive understanding of the emergence of religion, of applying an interdisciplinary approach, rather than a single approach with a very narrow explanation of religion or even within one specific religious tradition. Imagination, faith and hope emerged first and prepared us for the institutionalised religions practised today (Fuentes 2015, 2017; Van Huyssteen 2018:ad loc.). A long time before the initial appearance of modern humans we find ample evidence that our ancestors were developing significant and increasingly complex behavioural and cognitive responses to the social and ecological challenges they had to face in their niche (Fuentes 2017:213).

Everything known about the human history proposes that this behavioural and cognitive agility combined with increasing social cooperation and coordination, and the development of and experimentation with symbolic thought, enabled humans to create meaning in unique ways. At a particular point in the evolutionary process humans developed a new way of meaning making, especially by creating and using symbols. Therefore, humans are currently deeply immersed in a symbolic system where imagination, hope and the associated symbols can maintain stability and meaning and provide the necessary infrastructure for faith (Fuentes 2017:214). For both Van Huyssteen (2018:ad loc) and Fuentes (cf. 2015:7), this is a route to understanding religious thinking. The way the world is interpreted is a result of the interactions of various elements - brains, bodies, experiences, senses, other humans and animals and so forth. Humans, as both individuals and communities, are immersed in a world of thick symbolic landscapes, much of which is religious. Given this understanding of religious awareness and symbolic landscapes, Van Huyssteen (2006:267) emphasises that theologians are confronted with the responsibility of acknowledging the notion that the human capacity to respond religiously to ultimate questions - through various forms of worship and prayer - is profoundly implanted in the human species' aptitude for symbolic, imaginative behaviour, and in the embodied minds that enable such behaviour. This valuable interdisciplinary approach is, in my opinion, vital to any responsible theological perspective on what it means to be human. The study of the deep history of humans offers very little insight into today's institutionalised religions. It does, however, offer great insights into the human capacities for meaning making and into the ways in which this might relate to religious belief and practices. Lastly, it is important to note the limitations that come to light in an interdisciplinary dialogue on the capacity to be religious. Religious experience cannot be sufficiently explicated by either biology or the neurosciences. This is because of the fact that only the religious individual can interpret or identify a particular experience as religious or not. Therefore, an experience can only be qualified as religious or not by such a religious individual.
The methodological necessity for an interdisciplinary approach to the understanding and explanation of religion and religious experience is consequently illuminated by such an awareness of the limitations of scientific explanations. Thus, I argue that theology can and should play an indispensable role in exploring the emergence of our capacity for religious awareness and belief.

\section{The origin of morality}

An overview of the modern discourse on the origin of morality demonstrates the necessity of combining different perspectives, as no single perspective offers a comprehensive explanation of the origin of morality.

In this discussion on the origin of morality I draw on the perspectives of Frans De Waal, Michael Tomasello and Celia Deane-Drummond. De Waal (2013:289) advocates a bottomup view of morality. He bears in mind the fact that everything started simple, which is true for our bodies, minds and behaviour. Humans do not decide to be empathetic, they just are (De Waal 2006:23ff.). Such a bottom-up view of morality emphasises that the moral law is not imposed from above or derived from well-reasoned principles. It does, however, arise from deep-rooted values that have been there since the beginning of time. It is, however, at the group level that humans can be distinguished from other non-human animals. Human beings are intensely aware of the general well-being of the group, and therefore certain normative regulations were set in place to benefit the group. It is our very capacity for imagination which allows individuals to evaluate the impact of certain behaviour on the greater good for the society. Morality need not only be applied to within-group contexts, even though morality undoubtedly evolved for within-group reasons. An exploration of De Waal's (2005, 2006, 2013) work indicates the necessity of a biological perspective on human morality. For De Waal (2013:298), the main prerequisites or 'building blocks' for morality are empathy and reciprocity. Mutual exchange and emotional interest in other people are what characterise a moral society. In the light of the critique on De Waal's perspective on the origin of morality, I think it is important that we keep in mind that De Waal is not making an argument for animals as moral beings. De Waal does not at all claim that even chimpanzees possess morality. He does, however, maintain that human morality would not be possible without some proto-moral emotional building blocks that are noticeably at work in chimpanzee and monkey societies (Van Huyssteen 2017a:7). The presence of consolation and empathy in primates and humans is what constitutes De Waal's notion of proto-morality. Empathy, which is evident in especially chimpanzees, is required in social living. When De Waal (2013:131), then, argues that empathy connects bodies with bodies, he directly links the notion of emotional contagion - a process that requires imagination, conscious reasoning and analysis - with empathy. Human beings do not at any point decide to be empathetic, they just merely are.

Tomasello (2016) reconstructs how early humans gradually became ultra-cooperative and, eventually, a moral species. 
For Tomasello (2016:3; Tomasello et al. 2012:673-690), in short, there were mainly two evolutionary steps, of which each was founded on a novel way for individuals to act together as a plural agent 'we'. With the rise of ecological challenges that forced early humans to forage together collaboratively, or else they would die, the first step occurred. Humans developed cognitive skills of joint intentionality to coordinate these collaborative activities. These joint intentionality skills ensured that both partners were aware of the normative standards governing each role. Individuals, to reduce risk, can make a clear joint commitment that 'we' forage together and also share the spoils or rewards together as equally deserving partners. This is grounded in a shared sense of trust, responsibility and respect. The second step, for Tomasello (2016:3; Tomasello et al. 2012:673), took place as human populations grew larger and the division of labour became all the more complex. Distinctive cultural groups occurred that demanded loyalty, conformity and cultural identity from members. In becoming members of a new cultural 'we', modern human beings evolved cognitive skills of collective intentionality. The result was culturally created and objectified norms of right and wrong that all members in the group regarded as valid morals for anyone who would join the group and become one of 'us'. This two-step process resulted in contemporary humans having both a secondpersonal morality for face-to-face engagement with individuals and a group-minded 'objective' morality that obliges them to the moral community as a whole.

A third perspective that I find helpful in exploring the origin of morality is that of theologian Celia Deane-Drummond. I agree with Deane-Drummond et al. (2016:132) argument that a creative integration of the work from both theology and evolutionary theory can lead to a more comprehensive understanding of the origin of morality. Deane-Drummond $(2014,2017)$ is known for her development of a theological anthropology that seeks to take into account the implication of the lives of other animals in the evolution of human becoming. To avoid reductionist accounts of evolution, Deane-Drummond (2017:216) argues that niche construction - as discussed earlier in this article - is necessary in any discussion on the origin of morality. The mere notion that human moral and religious life did not happen in isolation from other animal kinds points to the significance of a niche construction perspective on the evolution of morality. Deane-Drummond (2014, 2015, 2017:216; Deane-Drummond et al. 2016:135) developed the notion of inter-morality, which suggests that interaction between species results, at least partially, in decision-making that has significant moral consequences. Closer attention to the variety of lives of other social animals can illuminate our understanding of human morality (Deane-Drummond 2014:122). In evolutionary terms then, in Deane-Drummond's (2014:122) argument, both human morality and animal morality are inter-morality if the unfolding guidelines of behaviour of a given species are entangled with that of another species. Deane-Drummond et al. (2016:135) therefore uphold that the morality of other animals, to the degree to which it exists or not, interacts with the growing sense of what is collectively considered to be right or wrong behaviour in specific communities. This is an alternative to De Waal's notion of the Tower of Morality. Deane-Drummond (2017:220) refrains from positing humans in a position of supremacy such as situated on the top of a Tower of Morality. If animals do actually have their own moral norms and worlds, then Deane-Drummond (2017:220) argues that inter-morality reflects a different kind of transversality between agents that are occupying different ecological niches, but simultaneously intertwining niches. Deane-Drummond et al. (2016:140) further suggest, and I agree, that theologians have a lot to gain from insights derived from the work on the human-animal interface. Such perspectives challenge the traditional notions of human exceptionalism, and are inclusive towards the importance of other animals. Such interdisciplinary accounts still remain challenging. The amount of epistemological weight to place on naturalistic accounts of the moral life, compared to the epistemological weight of theological traditions, is one of the most challenging judgements to make. It is also in this regard that Deane-Drummond et al. (2016:140) emphasise the importance of philosophy in unravelling the confusions that may arise.

This interdisciplinary dialogue on the origin of human morality presents a persuasive argument that evolution by natural selection can indeed explain the innate human sense of moral awareness, which is the human tendency to think in normative terms. Evolutionary explanations of this moral awareness cannot, however, explain human moral judgements. They also fail to justify the truth claims of any of the human moral judgements. How and why humans make moral judgements can only be illuminated on the level of the more interactive cultural evolution that is part of niche construction, a point that Deane-Drummond also supports. Along with a niche construction perspective, the historical deep dependence of human moral codes in religious and political conventions should be taken into account.

\section{Towards an interdisciplinary understanding of the origin of morality and religion}

Ricoeur develops an interesting notion of the human self in his well-known publication Oneself as Another (1992). I am of the opinion that Ricoeur's analysis provides us with a philosophical bridge theory from evolutionary anthropology to interdisciplinary theology, and I would like to add ethics. Ricoeur's striking notion of the human self is defined, at the most profound level, by time and narrative; other words, by the depth of its historical dimension. For Ricoeur (1992), the narrative dimension of human consciousness and selfawareness not only enables human beings to envision new projects, evaluate motivations and initiate viable courses of action, but the narrative dimension also enables us to empathise profoundly and identify with others. Ricoeur's (1992) narrative understanding offers us an ethics of responsibility, which consequently drives human beings, 
by means of empathy, beyond extreme self-reference to relationships with others. It is this extension of the 'circle of selfhood' that comprises an 'enlarged mentality ultimately capable of imagining the self in the place of the other' (Van Huyssteen 2017b:1). Thus, in Ricoeur's notion of narrative understanding, individuals are ultimately liberated from all-consuming self-absorbed or egoistic interests while maintaining their fragile identity as selves. For Van Huyssteen (2017b:1), such a narrative understanding produces a basic act of empathy through which 'the self flows from itself towards the other in a free variation of imagination'. Consequently, it can be argued that self-regarding is transformed by narrative imagination into a self-for-another. It is the power of imagination that enables the self to lace together numerous elements of a life into a single narrative.

In some way, Ricoeur's crucial themes of identity and ideas of 'selfhood' are revisited by Roger Scruton in his 2010 Gifford lectures, subsequently developed into a book The Face of God (2012). Scruton develops Ricoeurian ideas of selfhood further to take into account the central idea of the 'religious self', and ultimately God. Scruton starts his account from the point that a useful way of approaching what God's face is like is by beginning with the human face and the 'self' that expresses itself in it. Scruton (2010:37) proceeds from the observation that being present to another as a person is completely different from being in the locality of a simple objective thing. Being present to another as a person, similar to Ricoeur's view, is completely intersubjective. The moment one person acknowledges 'another' as a person, this instantly involves an entire range of reciprocal and morally charged relations. Consequently, the first-person perspective both empowers and limits the one who is capable of expressing it, subjecting one to the authority of obligation, but also opening one up to the prospect of love (O'Brien 2012:2; Van Huyssteen 2017b:2). Subsequently, for Scruton (2010:50), the question 'what and where am I in a world of objects?' is a necessary preliminary to the question 'what and where is God?' In this approach, the personhood that is revealed in the human face becomes extended to ultimately reflect the 'face of God'. In doing so, Scruton constructs the possibility for a bottom-up theological anthropology that wishes to illustrate that God's presence in the world is only discoverable if we attend to the nature and significance of human community. It is there that the face of God, in the person of Jesus Christ, has been made present to us (Scruton 2010:157, 2012:172).

I am of the opinion that Scruton's view of the religious self, along with Ricoeur's insightful vision of profound empathy for others, provides us with a pathway to bridge the gap between evolutionary and theological accounts. Integrating Scruton's view and Ricoeur's vision provides (in my research opinion) the best bridge theory for enabling a proposal for a bottom-up, contextual form of evolutionary ethics. I think it also prompts important questions about how this might apply specifically to the evolution of morality, ethical judgements, and the status of ethical judgements and moral codes in theology. Most significantly, both Scruton's and Ricoeur's perspectives imply a notion of morality and ethics, in this case a Christian ethics that is not developed in a 'top-down' framework with regard to duties, rights, rules, moral judgement and moral status. Rather, it is a 'bottom-up' view, which takes seriously the exploration of the fundamental evolutionary realities of human nature, in other words a natural history of morality. Such an approach, in my opinion, will bring us closer to developing a responsible ethics, which philosopher Philip Kitcher argues for in his work The Ethical Project (2011). For Kitcher (2011:207), it is often wrongly assumed that some authority is necessary in ethics, some position from which a certain truth can be reliably discerned. Kitcher (2011:207) argues, however, that this is not necessarily the way to view ethics as it may simply be something we work out together. Neither religion nor philosophy can proclaim with ultimate authority. For Kitcher (2011:207), in the end, the only authority is that of the ongoing conversation between people from diverse disciplines working it out together.

\section{Conclusion}

From the interdisciplinary approach to the human capacity for imagination, religion and morality, and its interdisciplinary conversations across diverse disciplines with several scholars at what I consider as the forefront of this current dialogue, I draw a number of conclusions. To acquire a more comprehensive understanding of human imagination, religion and morality, it is necessary to adopt an understanding of evolutionary anthropology, which is able to assist us in understanding what it means to be a natural, as well as a cultural, being with significant symbolic propensities. I am convinced that we can find a suitable framework for such an understanding in the niche construction theory. Key to the human capacity for symbolic behaviour is our equally significant capacity for imagination. In order for us to begin to comprehend the emergence of religious awareness and the moral sense, it is essential to find interdisciplinary points of connection over a wide range of explanatory frameworks whose focal points are not limited to merely one particular set of explanations of religion and morality. As is evident from the work of Fuentes, it is possible for us to link the origination of a distinctive human ecological and sociocognitive niche to existence in a world that is loaded with meaning. Consequently, this niche can also be linked to the development of an imagination that enables the capacity and skills for the prospect of metaphysical thought.

This research indicates that the emergence of religion can be found neither in adaptations through natural selection, nor in viewing religious belief as a mere by-product of human cognitive complexity. The emergence of, and capacity for, religious belief is a product of the interactive way in which humans all through prehistory have negotiated the world around them. The emergence of a human imagination and the manifestation of a quest for meaning as an essential part of the human niche are indeed a necessary precursor to 
having the capacity for religion. The same naturalness that applies to the human imagination also applies to the religious imagination. Van Huyssteen (2017a:6) makes the fascinating point that for Christian theologians this offers an exciting bottom-up view of the outstandingly complex way in which God has shaped and prepared the human species to be physically, mentally and spiritually 'ready' for faith. This is a point that I am not able to develop further because of the limited scope of this article.

Concerning the origin of morality, I argue it is within the framework of our unique human niche that we can find profound answers on the origin of moral awareness. It is also our very capacity for imagination which allows us to evaluate our actions in terms of other individuals and the wider society. Significant ecological changes within the human niche lead to greater complexity in collaboration and cooperation capacities, which, in turn, paved the way for the various forms of morality known in modern humans. I am also of the opinion that empathy remains one of the crucial precursors to morality. We do not at any given point decide to be empathetic - we just simply are. As is evident in the work of De Waal, empathy requires emotional contagion, and imagination is necessary in this process. Therefore, one can argue that it is our very capacity for imagination that connects bodies with bodies. In this view, empathy is the capacity to see deeply into another. In Ricoeur's line of thought, this can be translated as finding oneself in another. Empathy allows us to experience the density of another person. This whole process of awareness, that becomes selfawareness through our capacity for imagination, creates an ethical space within which an individual can evaluate his or her actions, thoughts and words in light of the other. How does all this then relate to ethics, specifically in the Christian tradition? In answering this question I would like to point to Kitcher's (2011:409) striking thesis that in a way links with the arguments of both Tomasello and De Waal. Our remote ancestors began the 'ethical project' tens of thousands of years ago. They introduced socially embedded normative guidance as a response to the difficulties and tensions of life together in small groups. Today, our ethical task is not over, as the ethical project is never finished. We have the great ethical task of deciding how to go on. With regard to Christian ethics, I am of the opinion that we cannot further this ethical project in a responsible way without an interdisciplinary approach combining theology with the sciences. A more comprehensive understanding of the deep roots of imagination, religion and morality can undoubtedly facilitate this important task.

As a final point, I consider the abovementioned findings of research as all the more reason for Christian theologians to acquire a more comprehensive understanding of some of the crucial aspects of being human - like imagination, morality and religious disposition - to construct a more responsible notion of ethics. The challenge, however, is to determine how differently ethical issues will be approached with a deepened understanding of morality and religious awareness, rooted in nature. By espousing a bottom-up view of morality, our approach to, and view of, prominent ethical issues regarding sexuality, gender and so on would be radically different. Interdisciplinary theology is able to responsibly reconceptualise Christian ethics, especially with reference to issues that call on being human. I argue that Christian theologians should take up the responsibility to continue to explore the constructive and vitally important ongoing contribution that theology can make in any discussion on religion, morality and ethics.

\section{Acknowledgements Competing interests}

The author declares that she has no financial or personal relationships that may have inappropriately influenced her in writing this article.

\section{References}

Deane-Drummond, C., 2014, The wisdom of the liminal: Evolution and other animals in human becoming, Wm. B. Eerdmans Publishing Co., Cambridge, MA.

Deane-Drummond, C., 2015, 'Deep history, amnesia, and animal ethics: A case for inter-morality', Perspectives on Science and Christian Faith 67(4), 268-271.

Deane-Drummond, C., 2017, 'Empathy and the evolution of compassion: From deep history to infused virtue', Zygon ${ }^{\circledR}$ 52(1), 258-278. https://doi.org/10.1111/zygo. 12317

Deane-Drummond, C., Arner, N. \& Fuentes, A., 2016, 'The evolution of morality: A three dimensional map', Philosophy, Theology and the Sciences 3(2), 115-151. https://doi.org/10.1628/219597716X14696202742055

De Waal, F.B.M., 2005, Our inner ape, Riverhead, New York.

De Waal, F.B.M., 2006, 'Morally evolved: Primate social instincts, human morality, and the rise and fall of "Veneer Theory", in S. Macedo \& J. Ober (eds.), Primates and philosophers: How morality evolved, pp. 1-75, Princeton Science Library, Princeton University Press, Princeton, NJ.

De Waal, F.B.M., 2013, The bonobo and the atheist: in search of humanism among the primates, Norton, New York.

Fuentes, A., 2009, Evolution of human behaviour, Oxford University Press, Oxford.

Fuentes, A., 2014, 'Human evolution, niche complexity, and the emergence of a distinctly human imagination', Time and Mind 7(3), 241-257. https://doi.org/ 10.1080/1751696X.2014.945720

Fuentes, A., 2015, 'Niche construction and religious evolution', Oxford Research Encyclopedia of Religion, viewed 10 April 2019, from http://oxfordre.com/ religion/view/10.1093/acrefore/9780199340378.001.0001/acrefore9780199340378-e-30.

Fuentes, A., 2017, The creative spark: How imagination made humans exceptional, Penguin Random House LCC, New York.

Fuentes, A., 2018, Lecture five: Why do we believe? A human imagination and the emergence of belief systems [Online], Gifford Lectures Blog, viewed 07 August 2018, from https://giffordsedinburgh.com/category/2018-professor-agustinfuentes-gifford-lecture-series/.

Kitcher, P., 2011, The ethical project, Harvard University Press, Cambridge, MA.

Mithen, S.J., 2007, 'Seven steps in the evolution of the human imagination', in I. Roth (ed.), Imaginative minds, pp. 3-30, Oxford University Press, Oxford.

O'Brien, M., 2012, Roger Scruton, The Face of God - Review, Academia Edu., viewed 15 August 2018, from https://www.academia.edu/1936618/Roger Scruton The Face_of_God_-_Review.

Parry, W., 2013, Exaptation: How evolution uses what's available, viewed 16 July 2017 from http://www.livescience.com/39688-exaptation.html.

Ricoeur, P., 1992, Oneself as another, University of Chicago Press, Chicago, IL.

Scruton, R., 2010, The Face of God. The Gifford Lectures [Lectures], Continuum International Publishing Group, New York.

Scruton, R., 2012, The Face of God. The Gifford Lectures, Continuum International Publishing Group, New York.

Serfontein, B., 2018, Imagination, religion, and morality: An interdisciplinary approach, $\mathrm{PhD}$ Thesis, University of Pretoria.

Smith, J.Z., 2004, 'Religion, religions, religious', in Relating religion: Essays in the study of religion, pp. 179-196, The University of Chicago Press, Chicago, IL.

Tomasello, M., 2016, A natural history of human morality, Harvard University Press, Cambridge, MA.

Van Huyssteen, J.W., 2006, Alone in the world: Human uniqueness in science and theology, Wm. B. Eerdmans, Grand Rapids, MI. 
Tomasello, M., Melis, A.P., Tennie, C., Wyman, E. \& Herrmann, E., 2012, 'Two key steps in the evolution of cooperation: The Interdependence hypothesis', Current in the evolution of cooperation: The Interdependence hyp

Van Huyssteen, J.W., 2017a, 'Lecture one: Rediscovering Darwin for theology Rethinking human personhood', HTS Teologiese Studies/Theological Studies 73(3), a4485. https://doi. org/10.4102/hts.v73i3.4485
Van Huyssteen, J.W., 2017b, 'Lecture two: The evolution of morality: The emergence of personhood', HTS Teologiese Studies/Theological Studies 73(3), a4487. https:// doi.org/10.4102/hts.v73i3.4487

Van Huyssteen, J.W., 2018, Human origins and the emergence of morality and religion, Gifford Lecture Series 2018, viewed 04 August 2018, from https://giffordsedinburgh com/category/2018-professor-agustin-fuentes-gifford-lecture-series/. 